\title{
Parliamentary Procedure: Previous Question ${ }^{1}$
}

\author{
James E. Dyer ${ }^{2}$
}

\section{Use of the Motion}

The motion Previous Question is used to immediately close debate and to prevent the making of all subsidiary motions, except for the motion to Lay on the Table. Ordering the Previous Question does not prevent the making of any privileged or incidental motions, has no effect on the last question considered by the assembly, and is not allowed in committees.

\section{Standard Descriptive Characteristics}

The subsidiary motion of Previous Question takes precedence over all other subsidiary motions except for the motion to Lay on the Table. In addition, the adoption of the Previous Question overrides the effect of the motion to Limit or Extend Limits of Debate. All privileged motions and those to which Previous Question can be applied take precedence over the Previous Question motion. The motion can be applied to a single debatable or amendable motion, the entire series of debatable or amendable motions, or to a portion of the debatable or amendable motions. No other subsidiary motions may be applied to the Previous Question except for Lay on the Table of the main motion, and if the motion is tabled, the Previous Question is adopted with the pending main motion.

A call for the Previous Question may not interrupt another member while he or she is speaking. The Previous Question requires a second, is not debatable, and is not amendable.
However, similar to an amendment, the Previous Question motion may be made a second time, including more or fewer pending questions.

The Previous Question requires a two-thirds vote. The affirmative vote on the Previous Question may be reconsidered before any vote has been taken under the rule of the Previous Question. If voting has already begun and the order has been partially executed, then the vote cannot be reconsidered. The motion is considered partially executed when applied to a series of motions and voting has begun after the order of the Previous Question. When voting has commenced on all pending motions under the order of the Previous Question, then the motion is to be considered fully executed.

\section{Further Rules and Explanations}

The use of the form "I call for the previous question" is a form of Previous Question in the nonstandard form and is subject to all rules that govern the Previous Question motion. This form still requires a second and a two-thirds vote for passage. The making of such motions may lead to unanimous consent to end debate. Before such motion is made, the chair may ask the assembly if there is any further debate or any objections to closing debate. No matter how the Previous Question motion is made, proper handling and procedures are still required for the motion to be in order.

If the Previous Question motion is ordered on a series of pending questions, then the motions are voted on in order

1. This document is WC138, one of a series of the Agricultural Education and Communication Department, Florida Cooperative Extension Service, Institute of Food and Agricultural Sciences, University of Florida. Original publication date January 2013. Visit the EDIS website at http://edis.ifas.ufl. edu.

2. James E. Dyer, professor, Agricultural Education and Communication Department, Florida Cooperative Extension Service, Institute of Food and Agricultural Sciences, University of Florida, Gainesville, FL 32611. 
of precedence, starting with the immediately pending question. For example, if the series included a main motion, Refer to a Committee, and Postpone Indefinitely, and the motion to Postpone Indefinitely was the immediate motion, the order in which the assembly would vote on these items would be refer, then the postponement, and finally the main motion.

Previous Question is considered to be exhausted when all motions under the order of the previous question have been finally disposed of, or when any other motions that have no effect on the previous question are disposed of. Exhaustions of the previous question are handled in the same manner as Limit or Extend Limits of Debate and follow whichever of the following rules comes first:

1. When all motions on which the Previous Question has been ordered have been voted on.

2. When those not yet voted on have either been committed or postponed indefinitely.

3. When the session in which the Previous Question was ordered ends.

After the Previous Question has been exhausted, any remaining questions that come up again are open for debate and amendments as if there had been no interruption of business.

\section{Form and Example}

"I move the previous question," is the form used when calling for the Previous Question in its general form. Acceptable forms also include "I demand" or "I call for the previous question." Members who wish to close debate on all items of business or a series of debatable or amendable items need only state, "I move the previous question on all pending items of business," or "I move the previous questions on immediately pending questions starting with (state which motion)." The calling of "Question!" by just one member in the assembly is not a form of the subsidiary motion of Previous Question, and the member is out of order if another member has the floor and is speaking.

\section{Example}

There are several debatable and amendable motions on the floor.

Member: Receives recognition from the chair and states, " $I$ move the previous question on all items of business."
Assembly: "Second."

Chair: "The previous question is moved and seconded on all pending questions. All those in favor of ordering the previous question please rise....Be seated. Those who oppose, rise... Be seated. There are two-thirds in the affirmative, and the previous question is ordered on all pending items of business. We shall now proceed to vote on... [start voting on the immediately pending question and then on the remaining in order of precedence].

\section{Reference}

Robert, H. M. (2011). Robert's rules of order newly revised (11 $1^{\text {th }}$ ed.). Philadelphia: DaCapo Press. 